\title{
La difusión de la aparcería durante la expansión triguera en un espacio de la región pampeana argentina. Marcos Juárez 1885-1905
}

\section{The Spread of Sharecropping Practices during the Wheat Expansion Period in an Area of the Pampas Region in Argentina. Marcos Juarez 1885-1905}

\author{
Luis A. Tognetti* \\ Centro de Investigaciones y Estudio sobre Cultura y Sociedad, \\ Universidad Nacional de Córdoba, Argentina, email: luistognetti@hotmail.com
}

Resumen. El objetivo del trabajo es brindar una explicación sobre el uso generalizado del arriendo a porcentaje para expandir el cultivo del trigo a zonas fronterizas de la región pampeana. Se toma en cuenta el interés de propietarios y aparceros a partir de una perspectiva diferente de la que se funda, casi exclusivamente, en la estructura concentrada de la propiedad. La hipótesis principal es que la aparcería resultó más conveniente para resolver los problemas que enfrentaron ambas partes para roturar las tierras vírgenes. Por un lado, los terratenientes lograron este objetivo sin sobrellevar los elevados costos de hacerlo con mano de obra asalariada o quedar expuestos a las limitaciones del contrato a renta fija. Por otro lado, los agricultores pudieron resguardar su participación en las mejoras realizadas sobre el suelo frente a las bruscas variaciones que experimentó la producción triguera durante este periodo.

Palabras clave: tierra agrícola; aparcería; arrendamiento.

Abstract. This paper aims to explain the generalized use of sharecropping practices to expand the frontiers of wheat production in the Pampas region. Such practices resulted from the combined interests of landowners and tenants -a different perspective from that based only on property ownership. The main hypothesis is that sharecropping appeared to be a more convenient method for both parties to solve the problems of working virgin lands. On the one hand, landowners could obtain benefits without incurring in the high costs associated with workers' salaries or running the risks and limitations of fixed- rent leases. On the other hand, tenants could safeguard their participation in land improvement in a period of harsh variations in wheat production.

* Agradezco el financiamiento recibido de Conicet, a través del PIP núm. 11220110100666/2012-2015, y los comentarios y sugerencias de Samuel Garrido y Juan Carmona. Asimismo, las observaciones realizadas por los evaluadores anónimos contribuyeron a mejorar la versión original del artículo.

Am. Lat. Hist. Econ., sep.-dic., 2017, pp. 71-104 | DOI: 10.18232/alhe.v24i3.772 
Key words: agricultural land; sharecropping; fixed-rent lease.

JEL: N86; N96; Q18.

Fecha de recepción: 6 de abril de 2016. Fecha de aceptación: 16 de noviembre de 2016 .

\section{INTRODUCCIÓN}

$\mathrm{E}$ 1 presente artículo analiza las razones por las cuales el arriendo a porcentaje resultó el contrato más difundido durante el periodo en el que la agricultura extensiva cerealera irrumpió en la región pampeana. Esta forma de aparcería ${ }^{1}$ un tanto híbrida, que se utilizó para la producción del trigo, fue sumamente criticada tanto por los funcionarios públicos encargados del análisis de la problemática agrícola (Río, 1899, p. 24) como por la mayoría de los autores que con posterioridad estudiaron el desarrollo cerealero argentino (Arcondo, 1996; Gallo, 1983; Scobie, 1982). Sin embargo, las diferentes interpretaciones realizadas dieron una respuesta parcial a la interrogante acerca de por qué resultó el contrato más escogido por propietarios y agricultores.

Como se propone, el arriendo a porcentaje permitió enfrentar algunos problemas experimentados por la agricultura extensiva que, en general, no han sido considerados en profundidad. En primer lugar, los autores consultados no tomaron en toda su dimensión las implicaciones de transformar las tierras vírgenes en cultivables y los elevados costos que se hubieran afrontado de haberla hecho con mano de obra asalariada. Tampoco advirtieron las limitaciones que enfrentaba el arriendo a renta fija durante la coyuntura en la cual se produjo el despegue de la exportación de trigo. Ambas restricciones, que afectaron principalmente a los propietarios, pudieron sobrellevarse de un modo más conveniente por medio de la aparcería.

En tanto, del lado de los agricultores, ese contrato les permitió expandir la transformación del suelo y no quedar expuestos a los riesgos que significaba hacerlo mediante el arriendo a renta fija. Este aspecto resulta fundamental si se toma en cuenta que tal transformación constituyó una parte importante de sus activos.

Y finalmente, aunque no menos importante, el contrato a porcentaje resolvió mejor el problema que para ambas partes significó la mayor variabilidad que mostraron los rendimientos del trigo durante el proceso de

${ }^{1}$ Definición ofrecida por Federico "Its distinctive feature is the division of the product between the parties according to some pre-determined share-out" (Federico, 2006, p. 262). 
roturación del suelo. Para comprender la dimensión de la problemática planteada es necesario tener presente el dinamismo que para la economía argentina tuvieron las ventas de los productos agropecuarios en el mercado mundial. En líneas generales, y a lo largo del siglo XIX, las exportaciones se expandieron por ciclos impulsados por el predominio de un producto en particular. Así, se sucedieron el cuero, el tasajo y la lana. De modo que, para fines de la década de 1870 los tres representaron $99 \%$ de las ventas al exterior.

A mediados del decenio siguiente se gestó un nuevo impulso fundado en el aporte del trigo y, en menor medida, del maíz y el lino. Para calibrar la magnitud de la contribución de estos artículos al comercio exterior argentino, conviene mencionar que se duplicó el valor en pesos oro de las exportaciones entre 1880 y 1894 . En relación con el monto correspondiente a este último año, 137000000 (pesos oro), el aporte del trigo alcanzó 20\%, que ocupó el tercer lugar detrás de las lanas y los cueros.

En los diez años siguientes la tendencia ascendente de las exportaciones se mantuvo para verificar un aumento de $82 \%$. En tanto, los productos agrícolas mencionados anteriormente representaron 50\% del comercio exterior argentino. En particular, los montos obtenidos por la venta del trigo se duplicaron hasta constituir $22 \%$ del total, con lo cual, el cereal desplazó al tercer lugar el aporte de los cueros (Díaz-Alejandro, 1983, pp. 18-19).

La breve síntesis realizada, respecto al desempeño exportador argentino, permite advertir que la investigación se concentra en los años en que el país sudamericano irrumpió en el mercado mundial del trigo como un actor protagónico; momento en el cual la agricultura extensiva avanzó sobre el espacio pampeano cordobés mejor situado respecto al puerto fluvial de Rosario, Santa Fe. El estudio se practicó sobre una porción de la región pampeana que en términos político-administrativos corresponde a la provincia de Córdoba y, dentro de ella, al departamento Marcos Juárez, cuya superficie rondaba en 1000000 de hectáreas.

\section{LAS FUENTES UTILIZADAS Y SU TRATAMIENTO}

La documentación utilizada correspondió a dos fuentes principales: los contratos de arriendo registrados en protocolos notariales y los informes o memorias de colonias. El seguimiento de la documentación notarial se practicó sobre seis registros de escribanos $(9,15,21,22,35$ y 40) con asiento en los departamentos de Unión y Marcos Juárez, ${ }^{2}$ entre 1885 y 1904

\footnotetext{
${ }^{2}$ La búsqueda abarcó los registros de ambos departamentos porque hasta 1888 Unión incluyó las tierras con las que luego se formaría Marcos Juárez. Pero, una vez creada la nueva
} 
inclusive. De este fondo documental se revisaron 81 protocolos y, debido a la limitada información que ofrecen los índices, fue necesario revisar cada una de las escrituras. De este modo, se identificaron 44 contratos correspondientes a arrendamientos, en dinero y a porcentaje, y a medianerías.

Si bien, el relevamiento demandó un esfuerzo considerable, el resultado alcanzado no fue de la misma proporción. Diversas causas lo explican; la principal es que durante el periodo no rigieron leyes que obligaran a registrar los contratos. Por lo tanto, sólo razones circunstanciales motivaron a pasar por el escribano los acuerdos entre propietarios y agricultores.

El conjunto de contratos reunido es valioso para conocer diversas características que presentaron esos acuerdos, aun cuando carezca de las condiciones que exige una muestra en términos estadísticos. Además, el contenido de cada uno de ellos es variable. Mientras en unos las cláusulas aportan muchos detalles acerca de la relación contractual, al establecer dimensiones, ubicación de la parcela, plazos, canon, exigencias de cultivo y formas de pago, en otros las precisiones son menores.

A pesar de esas limitaciones, los documentos obtenidos fueron útiles. Por un lado, sirvieron para precisar algunos aspectos que la información, cuantitativamente más rigurosa, no permitió alcanzar; por otro, los contratos reunidos fueron claves para identificar los problemas que la aparcería permitió resolver. Respecto a los informes o memorias de colonias, su elaboración estuvo a cargo de la Dirección de Estadística Provincial. Esta dependencia se organizó para proveer de información seriada a las autoridades públicas. Por esta razón, sus documentos siguieron, en general, los criterios de exhaustividad y periodicidad, indispensables para cumplir con aquel cometido. En cuanto a la confección de la memoria objeto de interés, para alcanzar la mayor amplitud informativa la dependencia designó un inspector por departamento, el que debía recorrer durante el mes de febrero. Las instrucciones impartidas por el director lo instaban a reunir la mayor información posible. ${ }^{3}$ Asimismo, la autoridad mencionada impuso

unidad político-administrativa, se decidió continuar la pesquisa sobre los registros con asiento en los dos departamentos, ante la posibilidad de que los pobladores de Marcos Juárez, por razones de comodidad, confianza u otras, siguieran concurriendo a los registros de la antigua unidad administrativa.

${ }^{3}$ Los principales datos relevados fueron los siguientes: nombre de la colonia, del fundador, del propietario al momento de la inspección y del administrador o persona que ejerciera función similar; superficie total y superficie cultivada y volúmenes cosechados por producto; distancia a la estación de trenes más cercana y al puerto; nombre de la línea férrea; cantidad de familias existentes discriminadas por nacionalidad y por su condición de propietarias o arrendatarias; número de cabezas de ganado, diferenciándolas por especie y por su destino, para las labores agrícolas o no; instrumentos de labranza existentes y diferenciados según utilización en tales labores: arado, siembra y cosecha (García-Delgado, 1898, pp. 109-110). 
pautas para controlar el itinerario desarrollado y asegurarse el relevamiento más extenso del espacio asignado. ${ }^{4}$

En cambio, llevó más tiempo sostener la periodicidad en la elaboración de la memoria ${ }^{5}$ y darle continuidad a partir de una edición propia. ${ }^{6}$ Este objetivo se logró recién a fines del siglo XIX y comienzos del XX.

De acuerdo con su contenido, la memoria de colonia se conformó de dos partes. La primera era de carácter general, y en ella el director de la dependencia hacía un balance que presentaba el total de los establecimientos relevados por departamento, la superficie de cada uno de ellos, los sembradíos por tipo de cultivos y las cantidades cosechadas. También se incluyeron comparaciones entre periodos, análisis de costos de producción del trigo y de los contratos celebrados entre propietarios y agricultores. En la segunda parte, la información reunida se presentó por departamento y colonia. Tras los años y con el aumento del número de las unidades a relevar, se procedió a la tabulación de los datos como una manera de reducir la extensión y sintetizar su contenido (Aguilar, 1901, 1902, 1903, 1904; García-Delgado, 1898, 1905; Río, 1899).

Pero, ¿cuán fidedigno de la realidad agraria del departamento Marcos Juárez fue el informe de los inspectores consultados? El interrogante se puede responder desde dos perspectivas. La primera surge de comparar la superficie del departamento con la alcanzada por el conjunto de las colonias inspeccionadas. Así, se constató que el primer informe disponible correspondiente a la campaña de 1895-1896 abarcó $49 \%{ }^{7}$ y en el último, el de la campaña de 1904-1905, la misma medición se situó en 63\% del territorio departamental (Aguilar, 1905).

La segunda perspectiva consiste en confrontar los datos reunidos con los provenientes de otra fuente cuantitativa. Por la temática tratada, es factible llevar a cabo este cruzamiento con la información provista por las cédulas censales correspondientes al segundo censo nacional practicado en $1895^{8}$ y por el censo agropecuario nacional de 1908 (Martínez, Latzina, León-Suárez y Lahite, 1909, vols. 1 y 2). De acuerdo con el contenido de

${ }^{4}$ Con esa finalidad, se les exigió informar telegráficamente del arribo y la partida de cada punto del itinerario preestablecido (García-Delgado, 1898, pp. 83-85).

${ }^{5}$ La memoria correspondiente a la campaña de 1895-1896 no se elaboró aunque se reunió la información en Manuscritos de los inspectores, Gobierno, Archivo Histórico Provincial de Córdoba (en adelante AHPC).

${ }^{6}$ En efecto, la memoria correspondiente a la campaña 1897-1898 se publicó como parte de la Compilación de leyes, decretos y demás disposiciones de carácter público dictadas por el Departamento de Hacienda de la provincia de Córdoba en el año 1898 (García-Delgado, 1898).

${ }^{7}$ Inspección de las colonias del Departamento Marcos Juárez, 1896, realizada por Eduardo Ortiz y Herrera. Gobierno, t. 271, leg. 2, AHPC.

${ }^{8}$ Segundo Censo de la República Argentina (10 de mayo de 1895). Cédulas Censales, Agricultura, Boletín núm. 27, Provincia de Córdoba, Archivo General de la Nación (en adelante AGN). 
las cédulas referidas, se pudo determinar que el relevamiento alcanzado en 1895 abarcó 25\% del territorio departamental. Es decir que, para tal año, la información producida por la dependencia provincial resultó más completa que la provista mediante el relevamiento nacional.

Respecto a la cobertura lograda con el censo agropecuario nacional de 1908, los responsables de la tarea extendieron la labor de los censistas hasta cubrir $90 \%$ del territorio departamental, superando sensiblemente las extensiones alcanzadas por los inspectores de la oficina de estadística provincial (Martínez, Latzina, León-Suárez y Lahite, 1909, vol. 1, pp. 7071, vol. 2, pp. 186-187). Aun así, los informes de esta última dependencia ofrecen un conocimiento más detallado de la realidad agrícola del espacio abarcado.

EL ARRIENDO A PORCENTAJE A TRAVÉS DE LAS FUENTES Y DE LA LITERATURA

Los primeros testimonios referidos al contrato objeto de interés se encuentran en los informes publicados por los funcionarios provinciales encargados del seguimiento de las labores agrícolas, cuyo contenido se evaluó en el apartado anterior. Los inspectores asignados a esta tarea lo definieron como un arrendamiento cuya particularidad fue que el alquiler se canceló con un porcentaje de la cosecha, que osciló entre 10 y $20 \%$. A su vez, lo diferenciaron de las medianerías por la magnitud de aquel porcentaje, 50\% en este último caso, y porque el propietario no aportaba otros elementos a la producción.

Los mismos funcionarios destacaron los resguardos excesivos que las cláusulas contenidas en los contratos brindaron a los propietarios y la principal consecuencia de este arreglo inequitativo, el comportamiento predatorio por parte de los agricultores (Aguilar, 1907, pp. XXIV-XXV; Río, 1899, pp. 23-24). Pero más allá del balance, ciertamente negativo, ${ }^{9}$ que elaboraron sobre el contrato a porcentaje, no aportaron elementos explicativos en cuanto a un interrogante fundamental, ¿̇por qué lo aceptaron los agricultores si en principio sólo benefició a los terratenientes?

Luego, el mismo contrato fue objeto de diversas revisiones por la historiografía, entre los distintos trabajos uno de los que en su momento mayor repercusión tuvo fue el de Scobie (1982). En él, el autor planteó que el contrato de arriendo se ajustó a los requerimientos de la ganadería

${ }^{9}$ Conviene referir que el balance de los funcionarios provinciales incluyó aspectos sociales además del estrictamente productivo. En esa valoración, la tenencia precaria era contrapuesta a la propiedad; en tanto, no resultaba funcional para radicar al hombre en el espacio y, por ello, poco contribuía a transformar un territorio, considerado en la época como un "desierto", en un ámbito “civilizado” (Río, 1899, p. 24). 
refinada, como consecuencia de lo cual la agricultura resultó subsidiara de aquella. De modo que los principales beneficiarios fueron los grandes propietarios rurales (Scobie, 1982, pp. 78-79). Pero su argumento, además de unilateral, es limitado porque no responde a la inquietud sobre cuáles fueron las ventajas de estos últimos cuando sus tierras se destinaron a la agricultura, exclusivamente.

Es importante destacar el aspecto mencionado al final del párrafo anterior porque existe una literatura abundante que ha indagado sobre la problemática del arriendo en la región pampeana a partir de la asociación que se produjo entre ganadería bovina refinada y agricultura. Dentro del conjunto de esos trabajos, el que ofrece una contribución más próxima a la problemática tratada corresponde al de Palacio (1992). En este texto, el autor da cuenta de por qué los estancieros recurrieron al arriendo a porcentaje para la producción de granos. Según su explicación, los grandes propietarios se sirvieron de esta forma contractual para eludir los riesgos que conllevó la actividad y para ajustar su extensión a las necesidades de la ganadería. En tanto, los agricultores la aceptaron debido a su situación precaria, originada en el manejo que aquellos realizaron con las dimensiones de los lotes asignados a la aparcería (Palacio, 1992, pp. 396-397). ${ }^{10}$

Sin embargo, son menos los textos que se concentraron en la cuestión del arrendamiento sobre tierras dedicadas sólo a la agricultura. Uno de los primeros en hacerlo fue Gallo (1983), quien al estudiar la colonización en Santa Fe acotó su análisis a un espacio donde la especialización triguera se manifestó tempranamente. Su explicación sobre la difusión del arriendo apuntó hacia las posibilidades que la maquinaria le brindó al agricultor para ampliar su explotación; en la medida en que al alquilar se liberaba de afrontar el monto correspondiente al valor de compra de una parcela más extensa. En cambio, el pago con un porcentaje de la cosecha se introdujo para preservar los ingresos del terrateniente frente a la depreciación sufrida por el dinero durante la década de 1880 (Gallo, 1983, pp. 98-99).

Además de otras contribuciones de la obra de Gallo (1983), su principal aporte a la cuestión tratada fue incorporar las razones que influyeron en el agricultor para optar por un contrato de arriendo. Pero su argumento está poco desarrollado y, por lo tanto, no toma en cuenta las restricciones que operaron a la introducción de maquinaria. Sobre todo cuando estas últimas se manifestaron en las innovaciones para potenciar la tracción. Esta problemática es abordada en el apartado dedicado a revisar el proceso de transformación del suelo.

Una observación diferente corresponde a la razón que ofrece Gallo (1983) para dar cuenta del paso del arriendo de renta fija a la variante ana-

${ }^{10}$ Véanse Cortés (1997), Palacio (2004), Reguera (1993) y Zeberio (1993). 
lizada en este artículo. Es posible que los problemas con el tipo de cambio promovieran esa modificación. Pero como se revisa en otro párrafo de este apartado, la difusión más intensa de esa modalidad se produjo cuando las fluctuaciones de la moneda se estabilizaron. De todos modos, y aun cuando esas hayan sido las circunstancias bajo las cuales se originó la transformación aludida, no da cuenta de las ventajas que encontraron propietarios y agricultores para proteger sus intereses mediante su introducción.

Más tarde, Sábato (1988, pp. 69-70) aportó otra explicación sobre la adopción del pago del arriendo mediante una parte de la cosecha. Por un lado sostuvo que el canon expresado como porcentaje del producto permitió al agricultor destinar sus recursos a los instrumentos y al capital de trabajo. Por otro, señaló que de ese modo se transformó el alquiler de un costo fijo en uno variable. Pero el aporte resulta insuficiente porque iniciarse como agricultor no demandó de un capital significativo y, además, existe evidencia de que cuando faltó se dispuso del financiamiento de comerciantes y acopiadores locales (Tognetti, 2014, p. 24).

Finalmente, Arcondo (1996, p. 43), a partir de datos censales, demostró que el sistema a porcentaje se difundió con mayor intensidad entre 1895 y 1914, por lo menos, en cuanto concierne al espacio pampeano cordobés. Su interpretación se fundó en la estructura concentrada de la propiedad que permitió a los terratenientes imponer aquel contrato por dos razones fundamentales: en primer lugar, lo prefirieron porque los protegía de la devaluación del dinero, y en segundo, porque les permitió apropiarse de los aumentos en el producto agrario. Respecto de la primera razón, como se señaló al evaluar el mismo argumento ofrecido por Gallo (1983), su validez resulta limitada porque temporalmente no coincidieron uno y otro fenómenos. En cuanto a la segunda, los aumentos en los rendimientos, su estudio no ofrece evidencia empírica que lo avale. Tampoco va en esa dirección el análisis practicado sobre los rindes del trigo, cuyos resultados se ofrecen en otra sección de este artículo.

El repaso realizado sobre la literatura revela que aún no se ha ofrecido una explicación que dé cuenta de la conveniencia que representó para ambas partes la adopción del contrato a porcentaje cuando la tierra se destinó sólo a la agricultura. En el mismo sentido, se puede afirmar que el foco no estuvo puesto en la problemática de la transformación de las tierras vírgenes en cultivables. La mayoría de los autores referidos perdió de vista que si bien una parte importante del territorio estuvo ocupada por poblaciones criollas o indígenas, hasta 1870 perteneció a la zona de frontera y que desde ese año, hasta el momento en que se desarrolló la especialización triguera, permaneció sin estar sometida a un laboreo sistemático.

La última cuestión señalada remite a un conjunto de interrogantes cuya respuesta ayudará a comprender mejor la dimensión de aquella pro- 
blemática. En primer lugar, ¿̇cuán significativas fueron las superficies a implantar?, segundo, ¿qué exigencias demandó ese proceso de transformación del suelo?, y tercero, ċen qué tiempo se produjo?

\section{LOS AVANCES DE LA PRODUCCIÓN TRIGUERA ARGENTINA A FINES DEL SIGLO XIX Y COMIENZOS DEL XX Y EL APORTE DE MARCOS JUÁREZ}

La experiencia de la agricultura extensiva del trigo en Argentina, durante la segunda mitad del siglo XIX, constituyó un claro ejemplo de transformación productiva; pues implicó no sólo un cambio en la localización de los cultivos, sino también en las prácticas empleadas para hacerlo. En este sentido, sus protagonistas debieron identificar las ventajas productivas que les permitieron convertir las tierras marginales en aptas para la producción del cereal en escala. De igual manera, adaptaron los instrumentos y las técnicas disponibles a otras condiciones ambientales, de modo que resultara económicamente viable la expansión sobre nuevos territorios (Djenderedjian, Bearzotti y Martirén, 2010, vol. 2, pp. 761-762).

Aunque no el único, un buen indicador del éxito conseguido con el patrón productivo extensivo es el aumento acelerado de las superficies implantadas y, consiguientemente, la presión que se ejerció sobre las tierras vírgenes. Las cifras resultan categóricas. A mediados de la década de 1870 se sembraron 130000 hectáreas, y a fines del decenio siguiente su extensión se multiplicó por seis. En tanto, para 1905 la superficie implantada con el cereal alcanzó 4900000 hectáreas (Djenderedjian, Bearzotti y Martirén, 2010, vol. 2, p. 533; Scobie, 1982, p. 210).

El epicentro de la producción triguera fue la región pampeana y, dentro de ella, las provincias de Buenos Aires, Santa Fe, Entre Ríos y Córdoba. Sin embargo, el ritmo que siguió en cada una de las jurisdicciones varió a lo largo del periodo considerado.

Hasta el primer lustro de la década de 1870, Buenos Aires albergó la mayor superficie cultivada, mientras que Santa Fe se ubicó en un segundo puesto. Para fines del decenio siguiente, estas posiciones se invirtieron y se ampliaron las extensiones sembradas en Entre Ríos y Córdoba. Hacia 1895, la primacía santafesina fue contundente, superando 1000000 de hectáreas y casi triplicando las extensiones alcanzadas por la producción triguera en el espacio bonaerense. Además, las superficies dedicadas al mismo cereal, en las otras dos provincias, crecieron entre cinco y seis veces (Djenderedjian, Bearzotti y Martirén, 2010, vol. 2, p. 533).

Para comienzos del siglo XX es posible advertir el inicio de un nuevo periodo expansivo que, a diferencia del anterior, tuvo su mayor intensidad, primero en Buenos Aires y luego en Córdoba. Las extensiones dedicadas 
al cereal en el caso bonaerense aumentaron más de cinco veces en 1905 hasta cubrir 2000000 de hectáreas, concentrando su jurisdicción 40\% de todas las tierras cultivadas con trigo en Argentina (Scobie, 1982, p. 210).

De todos modos conviene no perder de vista que durante la primera expansión, comprendida entre los años 1887-1888 y 1894-1895, se constató un mayor dinamismo que durante la segunda, acontecida entre 18971998 y 1904-1905. Mientras en aquella la tasa de crecimiento anual se ubicó en 13.6\%; en esta última estuvo en $9.5 \% .{ }^{11}$ En principio, y aunque no es una explicación suficiente, la diferencia de intensidad, a favor de la primera, puede atribuirse al dinamismo que le impuso a la actividad la depreciación sufrida por el dinero doméstico frente al oro. El deterioro en el valor del papel local se originó primero por las presiones sobre el mercado de cambios, a partir de 1887 (Gerchunoff, Rocchi y Rossi, 2008, pp. 94-95) $\mathrm{y}$, luego, por el déficit del balance de pagos como consecuencia de la crisis de 1890 (Ford, 1975, pp. 116-117).

La pronunciada desvalorización del circulante -cuyo cambio con el metálico pasó de 135 pesos en 1887 a 387 en 1891- significó una transferencia de ingresos considerable para los productores de bienes exportables (Ford, 1975, pp. 121 y 141), al punto que le permitió al trigo argentino competir en el mercado mundial aun cuando el precio del cereal mostró una tendencia declinante hasta 1895 (Gerchunoff, Rocchi y Rossi, 2008, p. 268) (véase cuadro 1).

Es importante agregar que, además del efecto generado por la devaluación de la moneda, la demanda internacional fue fundamental. Vale la pena señalar que en la década de 1890 la producción pampeana representaba $10 \%$ de la oferta mundial, y que su acceso a este mercado ocurrió en el momento en que Estados Unidos redujo su participación ante la necesidad de cubrir el aumento del consumo interno (Djenderedjian, Bearzotti y Martirén, 2010, vol. 2, p. 584). Así, a comienzos del siglo Xx, el incremento continuo de las superficies sembradas convirtió a Argentina en el segundo o tercer exportador, superada sólo por Estados Unidos y, en algunos años, por Rusia (Scobie, 1982, p. 112). En cuanto al destino del cereal argentino, los países europeos resultaron los principales compradores. En particular, para el periodo abarcado por este estudio tres países fueron los receptores más importantes: Gran Bretaña, Francia y Alemania (Carreras-Marín y Rayes, 2015, p. 208).

El crecimiento vertiginoso de las superficies implantadas con el cereal generó una presión sin antecedentes sobre tierras consideradas marginales hasta poco tiempo antes del éxito cerealero. En ese contexto hay que situar la irrupción del cultivo extensivo del trigo en la región pampeana cordobe-

\footnotetext{
${ }^{11}$ Para los cálculos de las tasas respectivas se tomaron los datos del cuadro 1.
} 


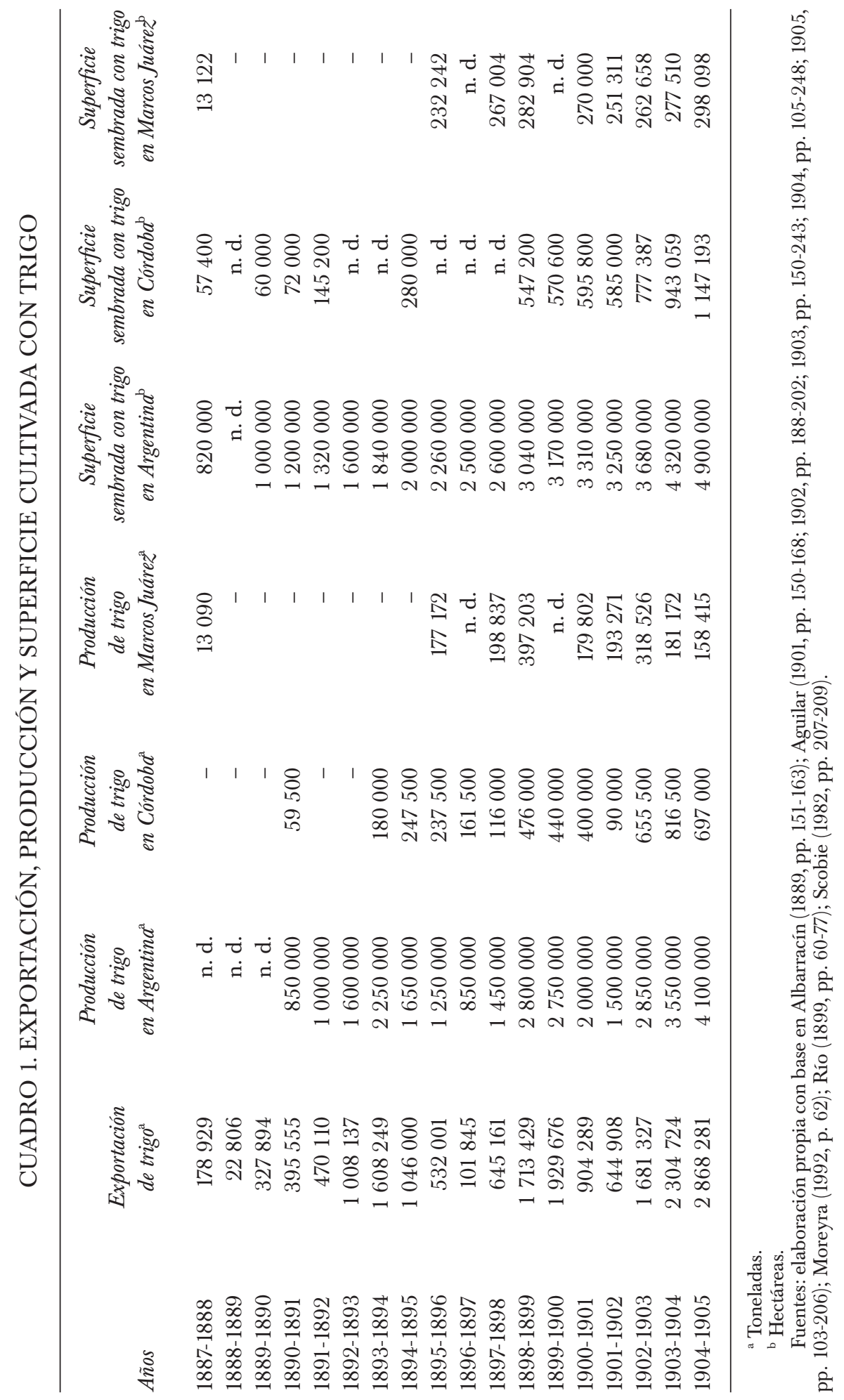


sa y, en forma más específica, en el departamento Marcos Juárez, correspondiéndose con la primera fase expansiva. Esta fue la etapa de amplio predominio de la agricultura dominada por la colonización santafesina.

Si bien la temática de la colonización escapa a los propósitos de este trabajo, su referencia es ineludible, fundamentalmente porque algunos de sus aspectos ayudarán a comprender mejor la cuestión tratada. Antes de avanzar sobre esos aspectos, es importante señalar que los dirigentes argentinos de la época depositaron grandes expectativas en la colonización; razón por la cual diseñaron diversos dispositivos con el objeto de impulsar su desarrollo. Sin embargo, algunos pocos se concretaron plenamente debido a la escasez de los recursos, tanto a nivel nacional como provincial. Además, la necesidad de obtener nuevas fuentes de rentas, para cubrir los déficits del erario, impulsó la venta del patrimonio inmobiliario conformado con el desplazamiento de la frontera sobre las poblaciones autóctonas. La enajenación de estas tierras privó al sector público de los espacios donde se habrían localizado las colonias promovidas por el Estado (Djenderedjian, Bearzotti y Martirén, 2010, vol. 1, p. 148).

Con el avance del siglo, las iniciativas oficiales a nivel nacional y provincial discurrieron por diferentes planos. Desde la órbita federal se establecieron diversos núcleos en las zonas donde el conflicto con otras naciones exigiera demostrar el ejercicio de la soberanía. Asimismo, en el segundo lustro de la década de 1880 se definió una nueva línea de acción en la materia consistente en comprar grandes campos a particulares en la región pampeana, para luego venderlos fraccionados y en cuotas a los inmigrantes. Sin embargo, el alcance de esta medida fue por demás limitado (Djenderedjian, Bearzotti y Martirén, 2010, vol. 1, pp. 175-176).

En cuanto a la órbita provincial, los dirigentes cordobeses optaron por establecer un marco regulatorio que ordenara el proceso de colonización llevado adelante por los particulares y, al mismo tiempo, estimulara la venta de la tierra a los colonos con la finalidad de ponerle un freno a la expansión de la tenencia precaria. Para ello, la legislación establecía exenciones impositivas para los titulares de las colonias que adhirieran a la iniciativa (Moreyra, 1992, pp. 146-147).

En sus manifestaciones más tempranas, las colonias se asentaron en Santa Fe y Entre Ríos, a mediados del siglo XIX. En los inicios tuvieron una finalidad estratégica de defensa y poblamiento y luego se orientaron hacia la producción de subsistencia (Djenderedjian, 2008, pp. 138-139). Sin embargo, por circunstancias que exceden a la problemática tratada en este artículo, para mediados de la década de 1870 se habían especializado en el cultivo del trigo y maíz a partir del desarrollo de un patrón extensivo que les permitió abastecer a las mayores ciudades del litoral fluvial (Martirén, 2013, p. 82). 
Pero, ¿qué era una colonia? Si bien existieron diferentes modalidades, se la puede caracterizar como un emprendimiento agrícola explotado por inmigrantes, en su mayoría europeos, que recibieron una parcela de diferentes extensiones, en propiedad o en arriendo. Con el tiempo, las dimensiones que alcanzó la modalidad dieron lugar a un negocio de compraventas de tierras fraccionadas (Martirén, 2015, p. 2).

Las circunstancias relatadas fueron aprovechadas con más intensidad por los núcleos asentados en Santa Fe. Asimismo, el conjunto de intereses que se constituyó en torno de aquellas encontró un estímulo para el desarrollo de nuevos emprendimientos con el trazado del ferrocarril Central Argentino, que unió Rosario con la ciudad de Córdoba en 1870. Este medio de transporte abrió una amplia franja de tierra hacia el oeste y atrajo a nuevos inversores de la ciudad portuaria interesados en colocar parte de sus excedentes, provenientes del comercio y el negocio inmobiliario urbano. Pero, sobre todo, impulsó la especialización triguera en el sureste cordobés y propagó el cultivo en secano sobre espacios carentes de una tradición agrícola extensiva (Martirén, 2013, pp. 84-85).

Las tierras del sureste provincial, jurisdiccionalmente ubicadas en Marcos Juárez, se encontraban en una posición inmejorable para recibir el avance de la colonización santafesina (véase mapa 1); no sólo limitaban con esta provincia, sino que, además, al iniciarse la década de 1890 eran surcadas por varias líneas férreas que las unieron al puerto de Rosario.

Su irradiación sobre el territorio cordobés alcanzó magnitudes destacadas (véase cuadro 2). En términos cuantitativos, el aspecto más relevante es que, en 1905, 747000 hectáreas se encontraban bajo aquel sistema, distribuidas en 96 colonias. ${ }^{12}$ Es decir que abarcó más de 70\% del territorio de Marcos Juárez, compuesto de 1035000 hectáreas.

En la misma perspectiva de análisis sobresale el fuerte incremento de la colonización ocurrida entre 1887 y 1892. En estos años, el número de nuevos emprendimientos fue de $47.49 \%$ de todos los que se crearon durante el periodo estudiado. Juntos sumaron una extensión de 410000 hectáreas, $55 \%$ de toda la superficie colonizada y $40 \%$ del territorio correspondiente a la jurisdicción abarcada. En tanto, en la superficie cultivada con trigo, maíz, lino y alfalfa se constata una intensidad mayor aún, entre 1887 y 1894 , con un crecimiento anual de 52 por ciento.

La información reunida ratifica la relación positiva que se generó entre la expansión de la colonización, bajo el modelo definido en Santa Fe, y

\footnotetext{
${ }^{12} \mathrm{El}$ conjunto de colonias abarcado en este estudio perteneció a 58 individuos, a tres sociedades comerciales y a tres compañías de tierras británicas. Respecto a los individuos se estableció que 22 residieron en la ciudad de Rosario, doce en Córdoba, diez en Buenos Aires y seis en el departamento Marcos Juárez. En relación con los ocho restantes no se pudo determinar su domicilio con precisión.
} 
ลे

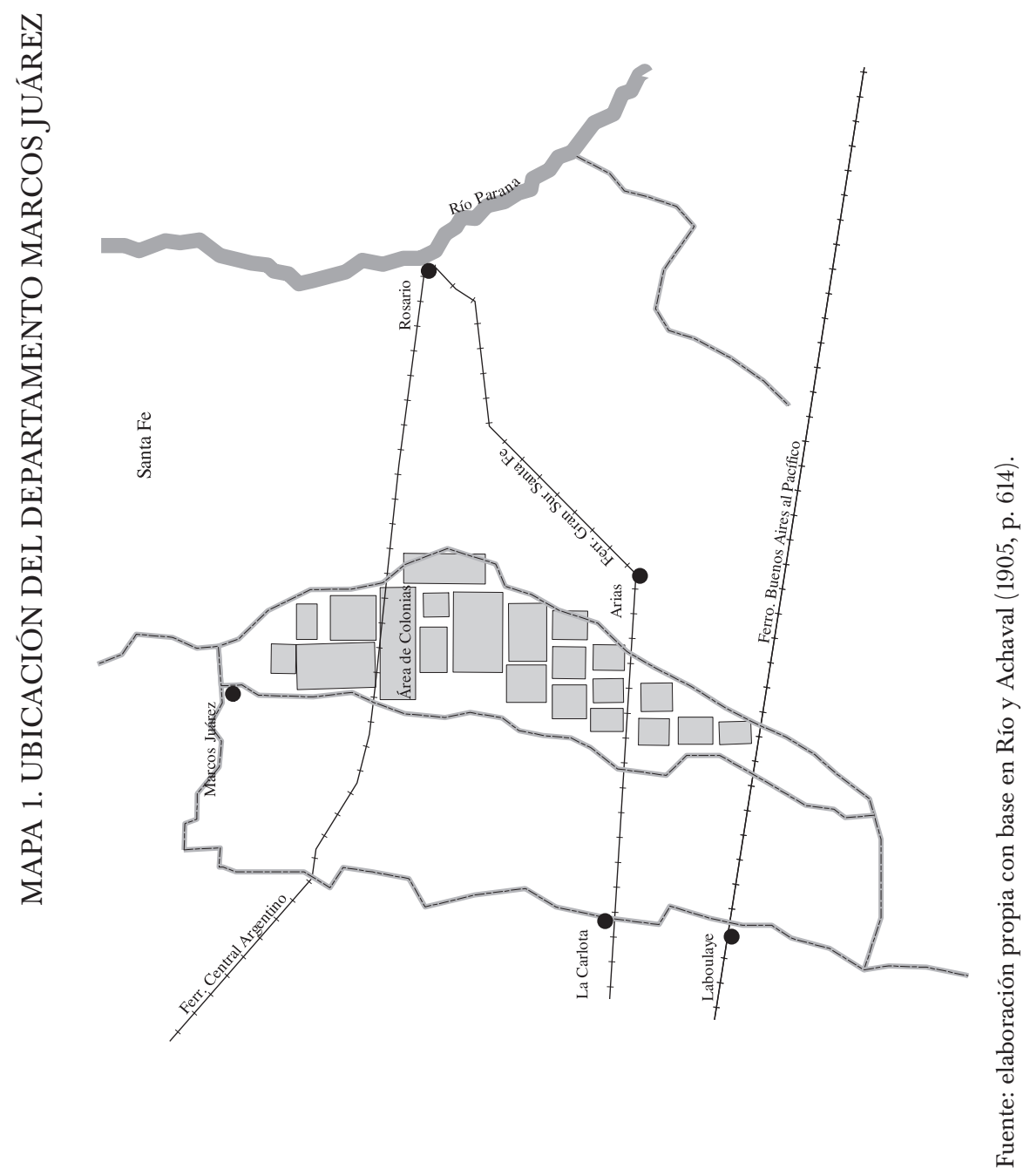




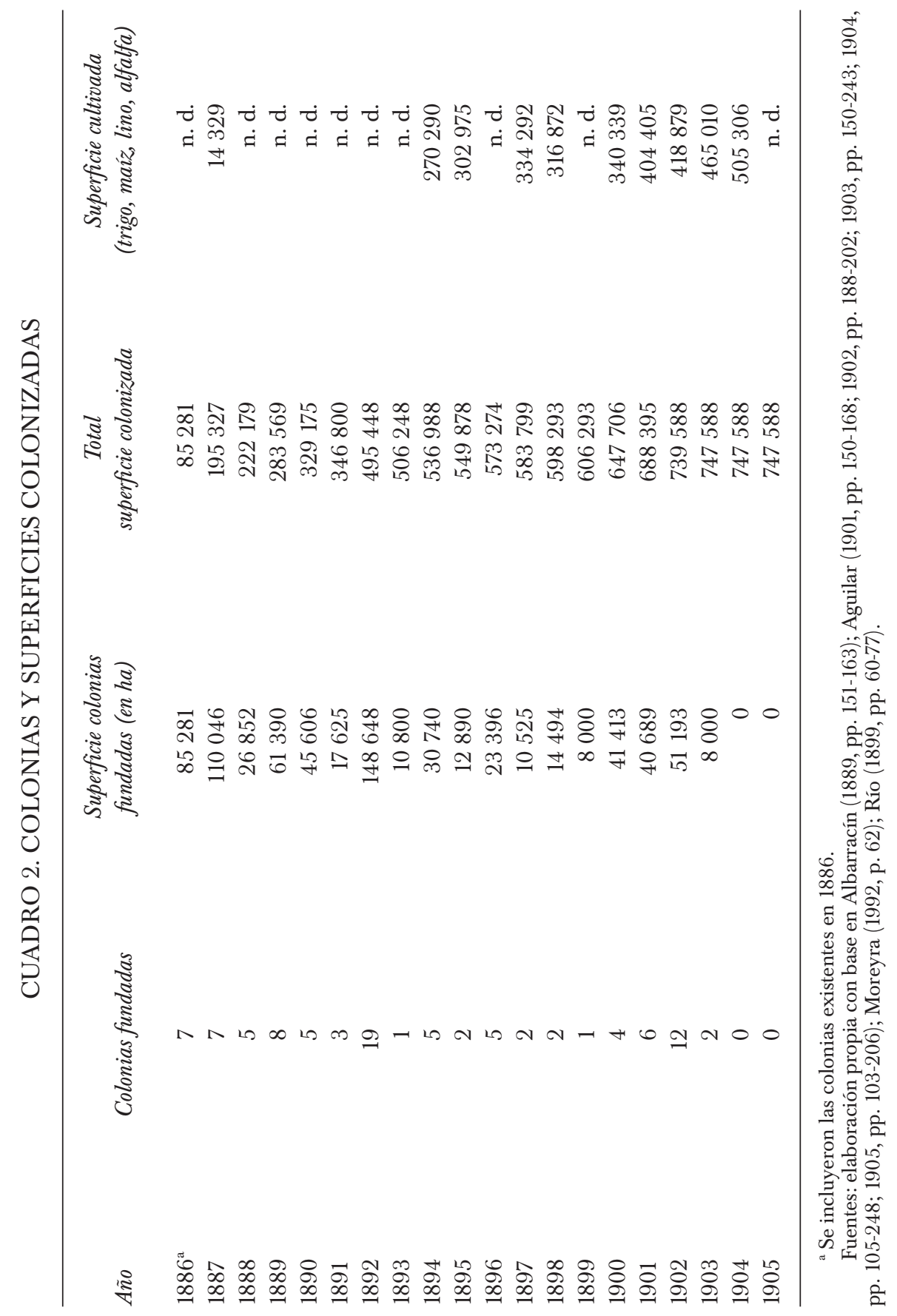


el cultivo extensivo del trigo en Marcos Juárez. Asimismo, se observa el fuerte predomonio del cereal que, hasta fines del siglo XIX, representó 90\% del suelo sembrado y luego $60 \%$ (véanse cuadros 1 y 2). Pero aunque los números reflejan el intenso proceso de expansión de los cultivos, conviene reiterar que las poco más de 500000 hectáreas cultivadas en 1905 correspondieron a tierras que hasta unos años antes permanecieron sin recibir ningún tipo de laboreo.

\section{LOS TRABAJOS NECESARIOS PARA LA TRANSFORMACIÓN DEL SUELO DURANTE LA EXPANSIÓN TRIGUERA SOBRE LAS TIERRAS DE MARCOS JUÁREZ}

En este apartado interesa indagar sobre algunos de los principales aspectos de la transformación operada en el suelo y no sólo su magnitud. También, se quiere exponer cuál fue la complejidad de los trabajos requeridos para la roturación y cultivo posterior, ${ }^{13}$ así como sus características.

En primer lugar, y dado que el espacio objeto de interés fue receptor del proceso iniciado en las colonias santafesinas, algunas de las innovaciones esenciales en la roturación y el labrado ya se habían realizado y se encontraban impuestas en las tareas culturales. De ellas, dos adaptaciones resultaron fundamentales para mejorar los rendimientos en las actividades referidas: la incorporación del arado doble y el uso masivo de la yunta de bueyes como forma de tracción. Respecto de la primera, la utilización de aquel instrumento permitió reducir hasta $80 \%$ los tiempos de trabajo destinados a esta actividad. Asimismo, la puesta a punto de esta innovación, a lo largo de la década de 1880, se evidenció en la mejora sensible que experimentó la ratio superficie-arados (Martirén, 2014, pp. 14 y 19).

Cuando la agricultura extensiva desarrollada en Santa Fe se difundió por el sureste cordobés, el arado antes aludido fue el instrumento con mayor presencia en los inventarios de los agricultores. Esta circunstancia se constató en los relevamientos de los inspectores enviados por el gobierno provincial y en los practicados por los censistas de 1895. De acuerdo con los datos reunidos por el inspector provincial en la campaña de 1895-1896, el número de aquellos instrumentos presentes en las colonias alcanzó las 7678 unidades. En tanto, la información vertida en las cédulas censales,

${ }^{13} \mathrm{El}$ análisis destaca las tareas de roturación y siembra. Es decir, que no se practica un estudio de todo el proceso de producción del trigo. Para llevar adelante esta indagación acotada se tomaron los testimonios registrados por dos funcionarios del gobierno provincial que actuaron como inspectores y del perito alemán Kaerger, encargado por su gobierno de estudiar la expansión del trigo en Argentina. Los años de los respectivos informes fueron 1896 (Kaerger, 2004), 1898-1899 (Río, 1899) y 1906-1907 (Aguilar, 1907). 
levantadas en mayo de 1895, dan cuenta de 3189 unidades de la misma herramienta. ${ }^{14}$

En cuanto a la utilización masiva de bueyes obedeció a diversas razones. Por un lado, este animal resultó más versátil para roturar las tierras. Por otro, los agricultores italianos, predominantes en las colonias argentinas, lo preferían tanto para realizar aquella actividad como para la labranza (Kaerger, 2004, p. 145). Ambas se conjugaron con su abundancia y baratura, lo cual permitió disponer de un mayor número y así renovar las yuntas y contar con más energía a lo largo de toda la jornada laboral (Kaerger, 2004, p. 148). Esta preferencia por los bueyes sobre otros animales de tiro se refleja en las cantidades existentes en las colonias. Por lo menos, en la campaña 1897-1898, el número de aquellos superó 73\% al de caballos y mulas sumados (García-Delgado, 1898, p. 84).

Conviene mencionar que, en cuanto a la preparación del suelo, en distintas ocasiones se experimentó con la propulsión a vapor, su potencia prometía reducir sensiblemente el número de jornadas laborales necesarias para llevar a cabo la faena. Sin embargo, tales intentos fracasaron por los siguientes motivos: requería mano de obra más calificada y mejor remunerada; incrementaba el costo en combustible, ${ }^{15}$ y exigía un aumento en las erogaciones de mantenimiento y en reparaciones. Además, existió otra razón: la mayor profundidad en la labranza, que requería la tracción a vapor, ${ }^{16}$ resultaba perjudicial para el cultivo del trigo (Kaerger, 2004, p. 145), como se verá más adelante.

Asimismo, por las características de la vegetación originaria no se necesitó de importantes tareas de desmonte, pero sí reiterar las roturaciones para eliminar las pasturas y pajonales naturales. La superficialidad de la técnica de arado combinado con las mejoras en la tracción animal permitieron avanzar sobre amplias extensiones año tras año, circunstancia que diferenció a la agricultura pampeana de otras (Kaerger, 2004, pp. 145-146).

\footnotetext{
${ }^{14}$ La variación en las cantidades de uno y otro relevamiento se explica porque el primero tuvo una mayor cobertura territorial, como se mencionó en un apartado anterior al revisar la calidad de las fuentes utilizadas. Sin embargo, la diferencia constatada se reduce considerablemente si se les compara a partir de la razón entre la superficie cultivada y el número de arados. El relevamiento provincial arroja una ratio de 39 hectáreas por instrumento y, en el segundo, el mismo cociente es de 53. Inspección de las colonias del departamento Marcos Juárez, 1896, realizada por Eduardo Ortiz y Herrera. Gobierno, t. 271, leg. 2, AHPC; Segundo Censo de la República Argentina (10 de mayo de 1895). Cédulas Censales, Agricultura, Boletín núm. 27, Provincia de Córdoba, AGN, Buenos Aires, Argentina.

${ }^{15}$ Con posterioridad al informe de Kaerger realizado en 1896, Miatello (1904, p. 200) destacó que los intentos de utilizar la tracción a vapor resultaron frustrados por el elevado costo del combustible.

${ }^{16}$ La información disponible indica que los rendimientos de la propulsión a vapor eran óptimos a los 40 o 50 centímetros de profundidad (Djenderedjian, Bearzotti y Martirén, 2010, vol. 2, p. 798).
} 
Si bien los testimonios utilizados para indagar en la cuestión coinciden en la descripción de los trabajos de preparación del suelo, las evaluaciones son discordantes. Por un lado, se cuestionó el modo en que se practicó el laboreo, por otro, se destacaron sus ventajas. Pero ¿̇cuáles fueron los puntos controversiales? Por lo menos, se detectaron dos. El primero correspondía con la intensidad y la profundidad a la que se debía realizar la roturación y el labrado. El segundo se refería a las extensiones abarcadas por los agricultores.

Evidentemente, el último aspecto, aludido en el párrafo anterior, no tenía que ver con las prácticas agrícolas pero sus consecuencias se manifestarían sobre estas, porque el afán por ampliar más allá de lo posible las superficies roturadas afectó el trabajo mismo de preparación del suelo, según sostuvieron quienes cuestionaron las técnicas de cultivo. En este sentido, las expresiones de un funcionario provincial, abocado a la cuestión, son elocuentes, "es debido al carácter extensivo de ellas [las prácticas culturales] que trata de simplificarlas al extremo de hacerlas imperfectas" (Aguilar, 1907, p. XVIII).

El cuestionamiento es importante porque según los mismos funcionarios públicos fue el contrato de arriendo a porcentaje el que permitió a los agricultores abarcar superficies mayores a sus posibilidades (Río, 1899, p. 28). Pero antes de avanzar sobre este aspecto conviene concentrarse en la objeción planteada a la técnica de roturación misma.

El punto central a dilucidar es el siguiente: ¿̇se trató de una práctica negligente o constituyó una modalidad adaptada a las condiciones edafológicas y climáticas pampeanas? Sin duda, dirimir esta disyuntiva excede los objetivos de este artículo; por lo tanto, se aportará información para comprender el problema de una manera menos unilateral del modo en que fue presentado por los funcionarios provinciales de la época.

Para tal propósito, se recurre a la comparación que llevó a cabo Kaerger (2004, p. 147), quien produjo uno de los testimonios utilizados para indagar en la problemática. Con su análisis comprobó que los rindes obtenidos por un conjunto de colonos que realizaron roturaciones más profundas fueron peores a los alcanzados por quienes emplearon métodos más superficiales. La explicación situaba la causa en que, la siembra a mayor profundidad, cuando se combinaba con agua en abundancia, ${ }^{17}$ traía como consecuencia que el trigo produjera más tallo y menos granos.

En cambio, los expertos agrónomos provinciales tomaron en cuenta los resultados obtenidos en las campañas que predominaron los años se-

${ }^{17}$ Este debate, también, se produjo entre quienes estudiaron la agricultura santafesina. Miatello (1904, p. 202), agrónomo experto, sostuvo que en los años lluviosos, también se constataba un rendimiento menor en la provincia vecina. 
cos, los más habituales; circunstancias bajo las cuales la siembra a mayor profundidad hubiera mejorado los rendimientos. Sin embargo, los agricultores al perseverar en su práctica cultural lo hicieron por otro motivo. En efecto, si las lluvias no los acompañaban, la cosecha fallaba pero los avances en la roturación, en transformar las tierras vírgenes, no se perdían. En este sentido, se puede sostener que eligieron la técnica en la que su esfuerzo no quedó tan expuesto a la condición climática.

Replanteada de esta manera la primera cuestión, se puede responder a la segunda. No fue la característica del contrato la que determinó una forma de roturación y laboreo, como acostumbraron a plantearlo los funcionarios públicos de la época. De hecho, aquellas se desarrollaron con anterioridad a la amplia difusión del arriendo a porcentaje.

Los argumentos presentados indican que la preferencia por la técnica en cuestión obedeció a las ventajas que reportaron para los mismos agricultores. No sólo porque pudieron beneficiarse con la ampliación del suelo cultivable, también por los resultados obtenidos de este modo. En este sentido, se demuestra que los rendimientos medios alcanzados por los productores trigueros en Marcos Juárez equipararon y, en algunos años, mejoraron los obtenidos en los departamentos vecinos de la provincia de Santa Fe (véase gráfica 1).

Finalmente, otro aspecto significativo corresponde al periodo en el cual se realizaron las labores de arado y siembra. Los tres testimonios reunidos coinciden en que estas se debían llevar a cabo entre marzo y mayo para un mejor aprovechamiento de las condiciones climáticas (Aguilar, 1907, pp. XVII-XVIII; Kaerger, 2004, pp. 145-148; Río, 1899, pp. 27-29).

Luego, las tareas cesaban casi por completo hasta fin de año. Entre noviembre y enero se llevaba a cabo la cosecha, meses en los que dependiendo del resultado se requería la mayor afluencia de mano de obra (Aguilar, 1907, p. XXIII).

Descritas sintéticamente las principales actividades relacionadas con la siembra del trigo es posible interrogarse sobre las alternativas que se le presentaron al propietario de cara al arriendo. La opción por el trabajo asalariado resultaba casi imposible. Esta modalidad se enfrentaba primero con la ajustada estacionalidad de las tareas culturales y segundo con la necesidad de contratar capataces para la vigilancia de las labores. ${ }^{18}$ Este costo se acrecentaba por la característica extensiva de la actividad. A ello hay que sumarle el incremento originado en la necesidad de contar con

\footnotetext{
${ }^{18}$ De acuerdo con Federico (2006, p. 266), "the managerial estate to be less efficient than either type of tenancy because wage labourers have little incentive to work hard, and supervising them is more difficult in agriculture than in the rest of the economy".
} 


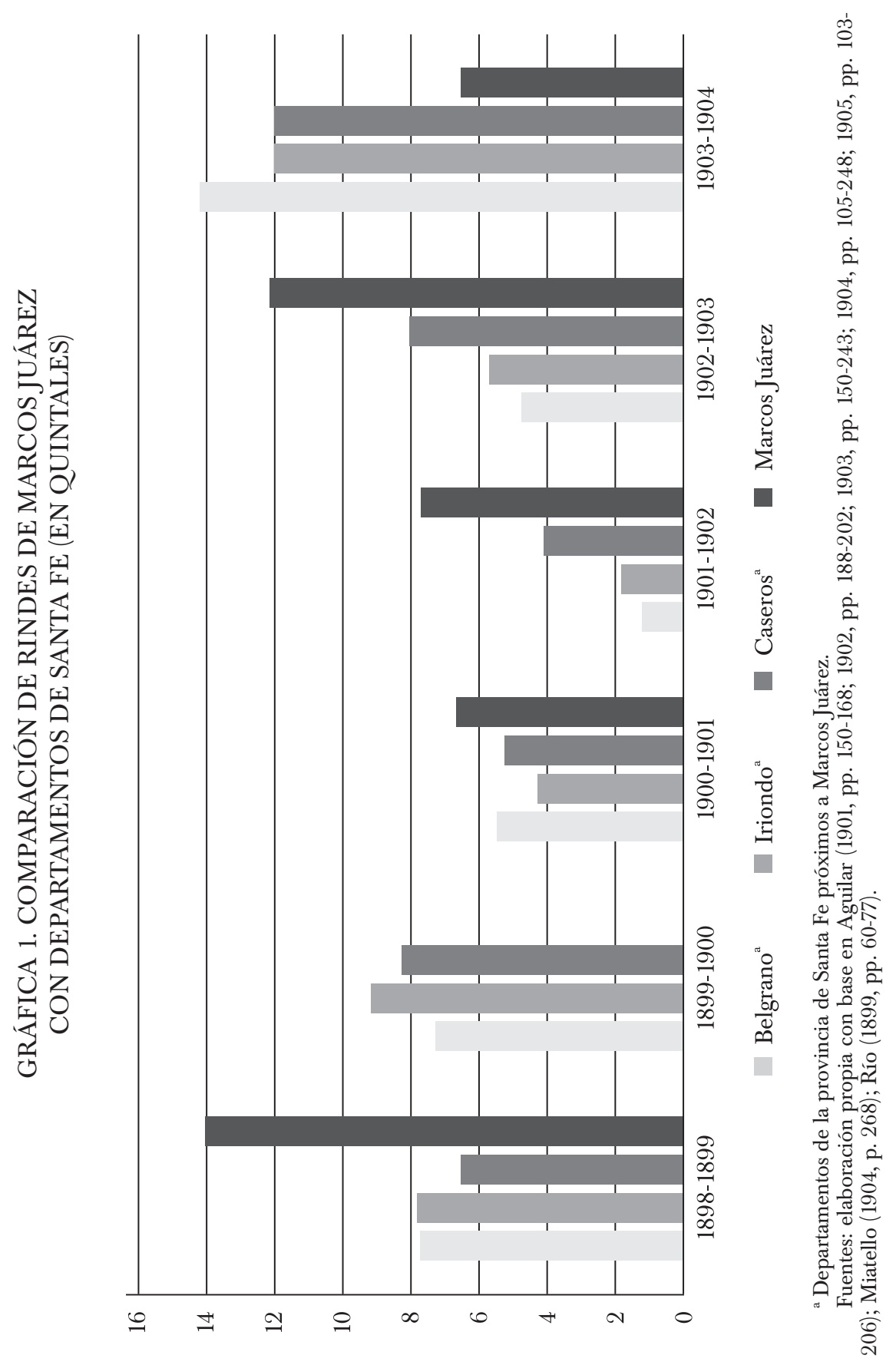


una administración local; pues la mayoría de los terratenientes, del espacio pampeano abarcado en este estudio, era absentista.

La gestión de la gran empresa agrícola se veía afectada, además, por la dificultad de estimar los ingresos esperados, debido a la amplia variabilidad que mostraron los rendimientos de la agricultura extensiva durante el proceso de transformación del suelo; circunstancia ante la cual el monto a pagar en salarios era inflexible. Y finalmente, no existieron economías de escala significativas que favorecieran la gran explotación (Kaerger, 2004, p. 178).

Los distintos aspectos referidos resultaron decisivos en cuanto a las ventajas que el arriendo reportaba para los propietarios y más aún si el pago del alquiler se pactaba en dinero, pues de este modo evitarían que sus ingresos menguaran por cuestiones climáticas. En este punto conviene recordar que los argumentos vertidos en la literatura acerca de las desventajas de un contrato de renta fija se fundaron en las depreciaciones sufridas por la moneda local (Arcondo, 1996, p. 43; Gallo, 1983, pp. 98-99). Sin embargo, como se dijo oportunamente, la mayor difusión del arriendo a porcentaje se verificó cuando el tipo de cambio ya se había estabilizado. ¿Qué razones pudieron pesar para que se difundiera este en lugar de aquel otro contrato?

La respuesta ofrecida a esa interrogante es que el arriendo en dinero presentaba una desventaja que se manifestó de forma contundente cuando las malas condiciones ambientales afectaron al conjunto de los cultivos, entre los años 1894 y 1897. Si bien el contrato de renta fija resultó conveniente al propietario, para el agricultor significó afrontar los malos resultados de manera directa. Ante la reiteración de un escenario negativo, se presentaron dos alternativas. Por un lado, si el fracaso de la cosecha desalentaba al arrendatario a continuar con las tareas podía transferir el contrato a otro dispuesto a continuarlo y, en el mejor de los casos, obtener un resarcimiento por las mejoras. ${ }^{19}$

Pero esa alternativa encontró un límite en el número de agricultores disponibles, cuya cantidad dependió de varios factores; uno de ellos el flujo migratorio. En este sentido, conviene señalar que durante la década de 1890 la corriente inmigratoria menguó considerablemente (Scobie, 1982, p. 207).

Por otro lado, existía la posibilidad de que el arrendatario no pagara y contrajera una deuda con el propietario, a cubrir con los resultados de

${ }^{19}$ Como se mencionó en el apartado dedicado a las fuentes, la búsqueda de contratos registrados en los protocolos notariales no arrojó un número muy significativo de casos; aun así, el material hallado muestra que se pagó un resarcimiento al arrendatario que abandonaba la explotación en reconocimiento por la mejora practicada en el suelo. Protocolos Notariales, registro 15, 1894 , f. 142 , y 1895 , f. 20 v., f. 345 v., AHPC. 
la próxima cosecha. ${ }^{20}$ Sin embargo, frente a la variabilidad de los rendimientos, esta opción aumentaba las probabilidades de que, ante un nuevo fracaso se incrementara su débito, transformando la huida en una salida atractiva. Y si bien, el agricultor se perjudicaría en forma inmediata, porque renunciaba al resarcimiento por las tareas de roturación; también, afectaba al propietario porque si no se continuaba con esa labor se arruinaría una parte de las mejoras realizadas.

En relación con el problema planteado, un contrato a porcentaje de la cosecha constituyó una opción conveniente al evitar que los malos resultados se convirtieran en deuda, al menos, con el terrateniente y, consiguientemente, se reducían los estímulos para abandonar la parcela. Además, y si por otras circunstancias, si el aparcero decidía dejar la explotación podía transferir el contrato y enajenar las mejoras realizadas en el suelo a un tercero, percibiendo como compensación una participación en la cosecha futura. ${ }^{21}$

Pero la aparcería se difundió con mayor intensidad cuando una seguidilla de malas cosechas, propias de un ciclo climático adverso, expuso a los propietarios a las desventajas del contrato a renta fija. Esta afirmación resulta avalada por las variaciones detectadas en las proporciones en que se distribuyeron las formas contractuales pactadas por los titulares de las colonias con los agricultores. Los resultados obtenidos del seguimiento realizado sobre los tres primeros informes disponibles, de los inspectores de colonias, van en esa dirección. Los cómputos practicados sobre la memoria correspondiente a la campaña de 1895-1896 arrojan que 33\% de las colonias recurrió al contrato de renta fija y 13\% combinó este con las medianerías. Un 30\% transfirió las tierras por medio de la venta y sólo 6\% utilizó el arriendo a porcentaje. Respecto del 18\% restante no fue posible determinar con precisión la forma contractual empleada. ${ }^{22}$

En el informe de 1897-1898 esas proporciones variaron del siguiente modo: 13\% de las colonias pactó contratos a renta fija y 23\% combinó esta modalidad con las medianerías. Los arriendos a porcentaje aumentaron

${ }^{20}$ Esta situación ha quedado documentada a través de dos contratos. La lectura del primero, registrado en 1896, revela que el arrendatario contratante tomó a su cargo la deuda pendiente dejada por su antecesor. Luego en 1898 se protocoliza un nuevo contrato en el que se deja asentado el cambio del titular del dominio. En este segundo documento se constata que la deuda por arriendos impagos se incrementó con las sucesivas campañas. Protocolos Notariales, registro 3, 1896 , f. 1435 , y registro 15,1898 , f. 250, AHPC.

${ }^{21}$ En un acuerdo de este tipo se estableció que la transferencia del contrato incluía el reconocimiento del "valor del trabajo hecho en el campo [...], en 170 cuadras de tierra que están rotas". En compensación por estas labores y por el uso de los útiles de labranza, el cedente percibiría $12 \%$ de la cosecha del siguiente año. Protocolos Notariales, registro 15, 1895, f. 69v., AHPC.

${ }^{22}$ Inspección de las colonias del departamento Marcos Juárez, 1896, realizada por Eduardo Ortiz y Herrera. Gobierno, t. 271, leg. 2, AHPC. 
$20 \%$ y las colonias que vendieron sus parcelas se mantuvieron en $30 \%$ (García-Delgado, 1898, pp. 113-183). Finalmente, la memoria correspondiente a 1898-1899 no registra colonias que pactaran sólo contratos a renta fija. El 17\% combinó esa modalidad con las medianerías. Mientras 44\% de las unidades relevadas utilizó el arriendo a porcentaje para ceder sus tierras a los agricultores. En tanto, las colonias que únicamente vendieron sus concesiones se mantuvieron en la misma proporción que en las campañas anteriores (Río, 1899, pp. 72-73).

De acuerdo con la explicación que se desarrolla, la preponderancia adquirida por el contrato a porcentaje -constatada durante la campaña de 1898-1899- se debió a la forma en que se enfrentaron las consecuencias del ciclo climático adverso sobre el proceso de roturación de tierras vírgenes. En efecto, se advierte que luego de 1898 se contrajo la extensión de la superficie cultivada, lo que constituyó una clara reversión de la tendencia ascendente verificada durante el primer lustro de la década (véase cuadro 1).

A comienzos de la nueva centuria, se reinició el proceso de transformación de tierras nuevas. Fue durante esta segunda etapa expansiva que el arriendo a porcentaje se tornó en la modalidad predominante de la agricultura triguera del sureste cordobés. A tal punto que, según los cálculos del inspector de colonias de 1906, bajo esa forma contractual se encontraba $70 \%$ de la superficie cultivada en ese año, aproximadamente 350000 hectáreas (Aguilar, 1907, p. XIII).

Pero, si la contingencia climática no se mantuvo en el tiempo, ¿̇por qué perduró la aparcería? La respuesta ofrecida es que las fuertes oscilaciones de los rendimientos del trigo expusieron a los terratenientes y agricultores de cada colonia a un efecto similar al que produjo el ciclo adverso antes referido a nivel departamental. Es decir que, para mantener las tareas de roturación, necesitaron del contrato que resguardara los intereses de ambas partes frente a las inclemencias que se sucedían campaña tras campaña.

\section{LA VARIABILIDAD DE LOS RENDIMIENTOS DE LA AGRICULTURA \\ TRIGUERA EXTENSIVA. SU MANIFESTACIÓN DURANTE LA ROTURACIÓN DE LAS TIERRAS VÍRGENES}

En el apartado anterior se mencionó en forma reiterada el fenómeno de la variación en los rendimientos de la cosecha del trigo. Sin embargo, a los efectos de hacer más comprensible la temática abordada es conveniente distinguir dos modalidades que adquirió aquel fenómeno. Por un lado, se identifica la que correspondió al proceso de transformación del suelo, entendiendo que la eficacia con la que se llevó a cabo esta tarea se manifestó en los rendimientos. Por otro lado, se constata la que obedeció a factores 
climáticos, sequías, inundaciones, heladas tardías, entre otros. Asimismo, y en relación con esta última dimensión del análisis, es posible indagar este aspecto a nivel de cada colonia, tomando en cuenta de qué modo resultó afectada la producción del cereal por las mismas circunstancias ambientales.

Para llevar adelante el análisis propuesto en sus diferentes niveles, se utilizó el rendimiento medio, que se entiende como la razón entre el total de quintales cosechado sobre la superficie cultivada, trabajando para cada grado de agregación -nacional, departamental ${ }^{23}$ o colonial- los valores correspondientes.

Las series resultantes, además de mostrar las tendencias seguidas por cada agregado y sus fluctuaciones recurrentes, facilitan la comparación entre los diferentes niveles de agregación con el fin de identificar los distintos fenómenos expresados en la variabilidad. Por ejemplo, la confrontación entre los resultados a escala nacional con los alcanzados en el conjunto departamental sirve para identificar el impacto debido al proceso de transformación del suelo. Por su parte, la seguidilla de campañas con malos rindes permite constatar la ocurrencia del ciclo climático.

En cambio, cuando se coteja la discrepancia entre el rinde de una colonia y el promedio del conjunto formado por todas, se aprecia la influencia que las condiciones climáticas ejercieron sobre las parcelas explotadas en la primera. Esta perspectiva es la que más se aproxima a los efectos percibidos por los agricultores y el propietario frente al fenómeno de la variabilidad. En este sentido, es razonable suponer que las decisiones de ambos tomaron en cuenta las fluctuaciones ocurridas a esta escala más que a las acontecidas en la agregación departamental.

Para llevar a cabo cualquiera de las modalidades de análisis aludidas, el principal obstáculo se encuentra en la disponibilidad de la información. La búsqueda realizada permitió ubicar los datos correspondientes a ocho de los 18 años comprendidos por este estudio (véase cuadro 3). Pero, además de limitada esta información, no está repartida de manera homogénea a lo largo de todo el periodo tratado. Existen más lagunas hasta 1900 que con posterioridad.

Frente a ese problema se puede recurrir a los resultados de las campañas a escala nacional, ${ }^{24}$ como una manera de aproximarse a la tendencia

${ }^{23} \mathrm{El}$ rendimiento medio en el caso departamental corresponde al conjunto de las colonias y se obtuvo del modo indicado más arriba y no mediante el promedio de los rindes de cada colonia. Es importante mencionar que siguiendo aquel procedimiento se obtuvieron 379 rindes.

${ }^{24}$ Los rindes en quintales de las campañas agrícolas a nivel nacional fueron los siguientes: 1890-1891 7.08; 1891-1892 7.58; 1892-1893 10; 1893-1894 12.23; 1894-1895 8.25; 1895-1896 5.53; 1896-1897 3.40; 1897-1898 5.58; 1898-1899 9.21; 1899-1900 8.68; 1900-1901 6.04; 1901-1902 4.62; 1902-1903 7.74; 1903-1904 8.22 y 1904-1905 8.37 (Scobie, 1982, pp. 207-209). 
seguida por la producción en Marcos Juárez y de esta forma cubrir el bache informativo. Esta posibilidad se sustenta en que durante la década de 1890 entre 60 y 70\% de la producción triguera argentina correspondió a Santa Fe y Córdoba (Scobie, 1982, p. 211). A su vez, Marcos Juárez aportó entre 75 y $80 \%$ del cereal correspondiente a la segunda provincia. Respecto a las colonias se evidencia que en los años para los que se dispone de menor cantidad de datos se constatan movimientos en la misma dirección, tanto a escala nacional como local (véase cuadro 3).

Formuladas esas aclaraciones, es posible concentrarse en el modo en que se manifestó la variabilidad, ¿qué amplitud tuvo este fenómeno?, ¿estuvo presente en la producción nacional?, ¿ifue de la misma intensidad a nivel local? El análisis sobre los quince rindes nacionales arroja una amplitud considerable, pues mientras el rendimiento mínimo se ubica en 3.40, el máximo alcanza a 12.33 quintales por hectárea. Es decir, que las variaciones verificadas fueron de una magnitud superior a las tres veces. Además, $50 \%$ de los valores se ubica por debajo de 7.74 quintales por hectárea y el valor más repetido se encuentra en torno a ocho quintales. Los parámetros referidos indican que los rendimientos anuales están dispersos y escasamente agrupados en torno de un valor representativo. A partir de la evidencia analizada, es posible afirmar que la producción triguera, a escala nacional, se caracterizó por una marcada inestabilidad en los rendimientos.

Respecto de la misma información disponible para el caso de Marcos Juárez, los valores extremos hallados corresponden a 5.31 y a 14.04 quintales por hectárea. Pero como se cuenta con información incompleta podría ocurrir que no fueran esos los rendimientos extremos registrados por la producción triguera. Por lo menos, esta sospecha se encuentra fundada, para el caso del valor mínimo, porque, según se desprende del informe elaborado por la oficina de estadística provincial, en la campaña de 1896-1897 se obtuvieron menos de cuatro quintales por hectárea (GarcíaDelgado, 1898, p. 100).

La evidencia parcial reunida sugiere que el rasgo indagado de la producción triguera pampeana se manifestó en forma más acusada en Marcos Juárez. Esta constatación avala la suposición sostenida en este artículo en cuanto a que esa mayor intensidad estuvo asociada al proceso de transformación del suelo virgen y, su perduración en el tiempo, a la necesidad recurrente de expandir los cultivos sobre tierras nuevas.

En otra dirección, el análisis practicado a nivel del agregado nacional corrobora la existencia de un ciclo climático adverso entre las campañas de 1895-1896 y 1897-1898, circunstancia parcialmente corroborada por los valores medios correspondientes al agregado del conjunto de colonias. De 


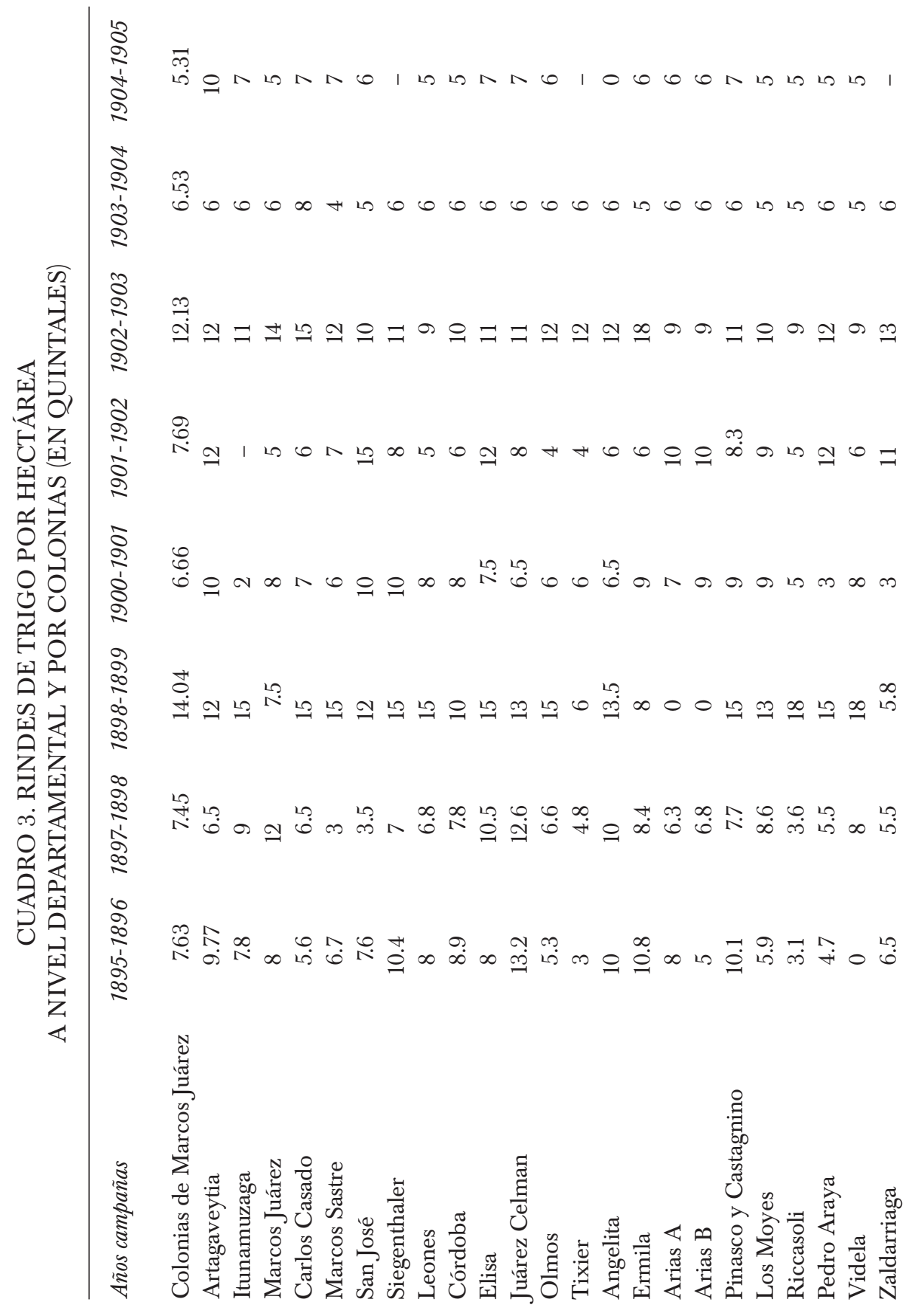


0 r 0 NNN

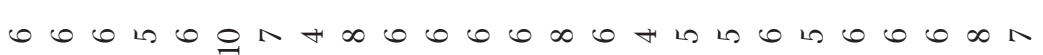

으는

$\exists 00$ 음 0 으

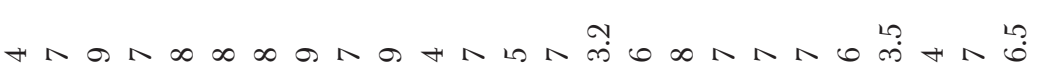

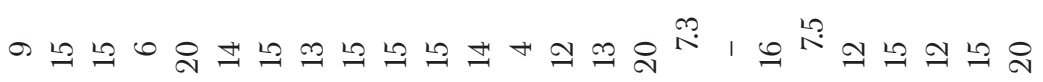

舟

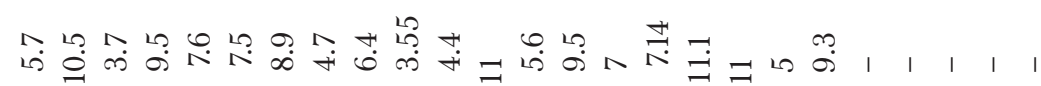

के

$\dot{0} \dot{0}$

เू

ㅇำ

$\ddot{\infty}$

实

는

욜

ㅎํㅇㅇㅇㅇ

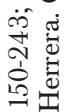

곤

भ

응

จิ สำ

$\infty$ 되

흥

हี

จิ ปี

$\dot{2} \ddot{0}$

늉잉

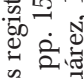

先家焉

च ठ ठ

층 츨

을

ᄋㅇㅇㅇ

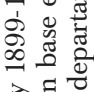

스웜

क

ڤ́

등 웅

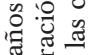

을

สิ

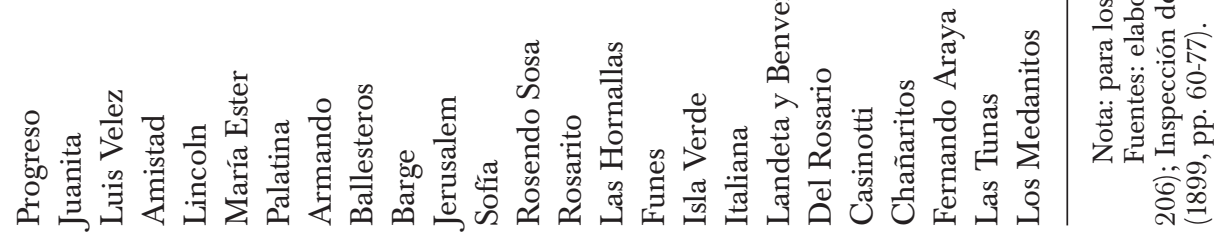


las tres campañas, la que arrojó la cosecha más escasa fue la de 1896-1897, en la que se obtuvo menos de cuatro quintales por hectárea.

Pero, ¿qué significó para el agricultor ese resultado? Aunque no se dispone de una cifra exacta para la campaña 1895-1896 se necesitaron entre dos y tres quintales de trigo para cubrir los costos de labrado y siembra (Kaerger, 2004, pp. 186-188). Si el promedio se ubicó por debajo de cuatro, una parte de los productores no recogió la cantidad requerida para cubrir esos gastos. Para tener una verdadera dimensión de la magnitud del problema, hay que tener en cuenta que una proporción de quienes obtuvieron una magra cosecha, arrastraba, a su vez, deudas de la campaña anterior con las casas comerciales que adelantaron parte de los recursos necesarios para cubrir los gastos de ambas tareas y que no pudieron devolver con los rindes obtenidos. ${ }^{25}$

Si se pasa al análisis del agregado colonial, se verifica que la variabilidad fue más acusada (véase cuadro 4).

Asimismo, es factible constatar que la posibilidad de alcanzar un rendimiento menor a los costos de laboreo y siembra se hizo presente en otros periodos ajenos al ciclo climático antes referido. Si la lectura del cuadro 4 se detiene en los valores mínimos se puede advertir que en tres colonias, al menos en una campaña, los resultados fueron nulos. Además, en quince colonias se cosecharon tres o menos quintales por hectárea y otras quince obtuvieron cuatro o cinco quintales. Es decir que en 30 de las 48 colonias, para las cuales se dispone de la información de interés, sus rindes se ubicaron entre cero y cinco quintales, en alguna de las campañas abarcadas por este estudio.

En los distintos años agrícolas, las cosechas de cada colonia experimentaron fuertes oscilaciones; en 23 colonias de las 48 registradas, las variaciones entre los menores y los mayores rendimientos fluctuaron entre diez o más quintales por hectárea (véase gráfica 2).

La intensidad de la variabilidad reflejada en los rendimientos mínimos y máximos es una evidencia contundente de la incertidumbre que caracterizó a la producción triguera durante el periodo tratado y reafirma el argumento sostenido al final del apartado anterior en cuanto al motivo por el cual el contrato a porcentaje perduró después de acontecido el ciclo climático.

El estudio del agregado colonial ofrece una perspectiva más adecuada para dimensionar el efecto de la variabilidad sobre los protagonistas de la producción triguera (véase cuadro 3). El significado de esta última afirmación se comprende mejor si la atención se concentra en los rindes de la

\footnotetext{
${ }^{25}$ Inspección de las colonias del departamento Marcos Juárez, 1896, realizada por Eduardo Ortiz y Herrera. Gobierno, t. 271, leg. 2, AHPC.
} 


\section{CUADRO 4. RINDES OBSERVADOS EN LAS COLONIAS DE MARCOS JUÁREZ (EN QUINTALES)}

\section{Rindes}

mínimos y máximos

$0 * 10$

$0 * 18$

$2 * 15$

$3 * 12$

$3 * 13$

$3 * 14$

$3 * 15$

$3 * 18$

$4 * 11$

$4 * 12$
Rindes

Repeticiones mínimos y máximos

$4 * 13$

$4 * 20$

$5 * 12$

$5 * 13$

$5 * 14$

$5 * 15$

$5 * 16$

$5 * 18$

$6 * 20$

$7 * 17$
Repeticiones

2
1
1
1
2
3
2
1
1
1

Fuentes: elaboración propia con base en Aguilar (1901, pp. 150-168; 1902, pp. 188-202; 1903, pp. 150-243; 1904, pp. 105-248; 1905, pp. 103-206); Inspección de las colonias del departamento Marcos Juárez, 1896, realizada por Eduardo Ortiz y Herrera. Gobierno, t. 271, leg. 2, AHPC; Río (1899, pp. 60-77).

campaña de 1898-1899. Es fácil advertir que se trató del año con la mayor dispersión de todos los que contiene el cuadro 3, registrándose los valores extremos de 20 y cero quintales por hectárea. Sin embargo, el agregado departamental arroja el promedio más elevado de todo el periodo seleccionado. Es decir, que este último nivel de análisis no permite apreciar la situación de diversos productores, que en esa misma campaña obtuvieron un resultado con el cual no pudieron cubrir los costos de implantación del cereal.

La dispersión en los rendimientos tendió a morigerarse, observándose una mayor aglomeración de los datos a partir de comienzos del siglo XX (véase cuadro 3). La tendencia detectada es coincidente con la segunda fase expansiva, identificada en un apartado anterior. En esta la proporción de tierras vírgenes respecto de las cultivables se redujo, debido a la menor intensidad que registró el proceso de transformación del suelo y a que, para una parte considerable de las tierras de Marcos Juárez, ese proceso se había completado. 


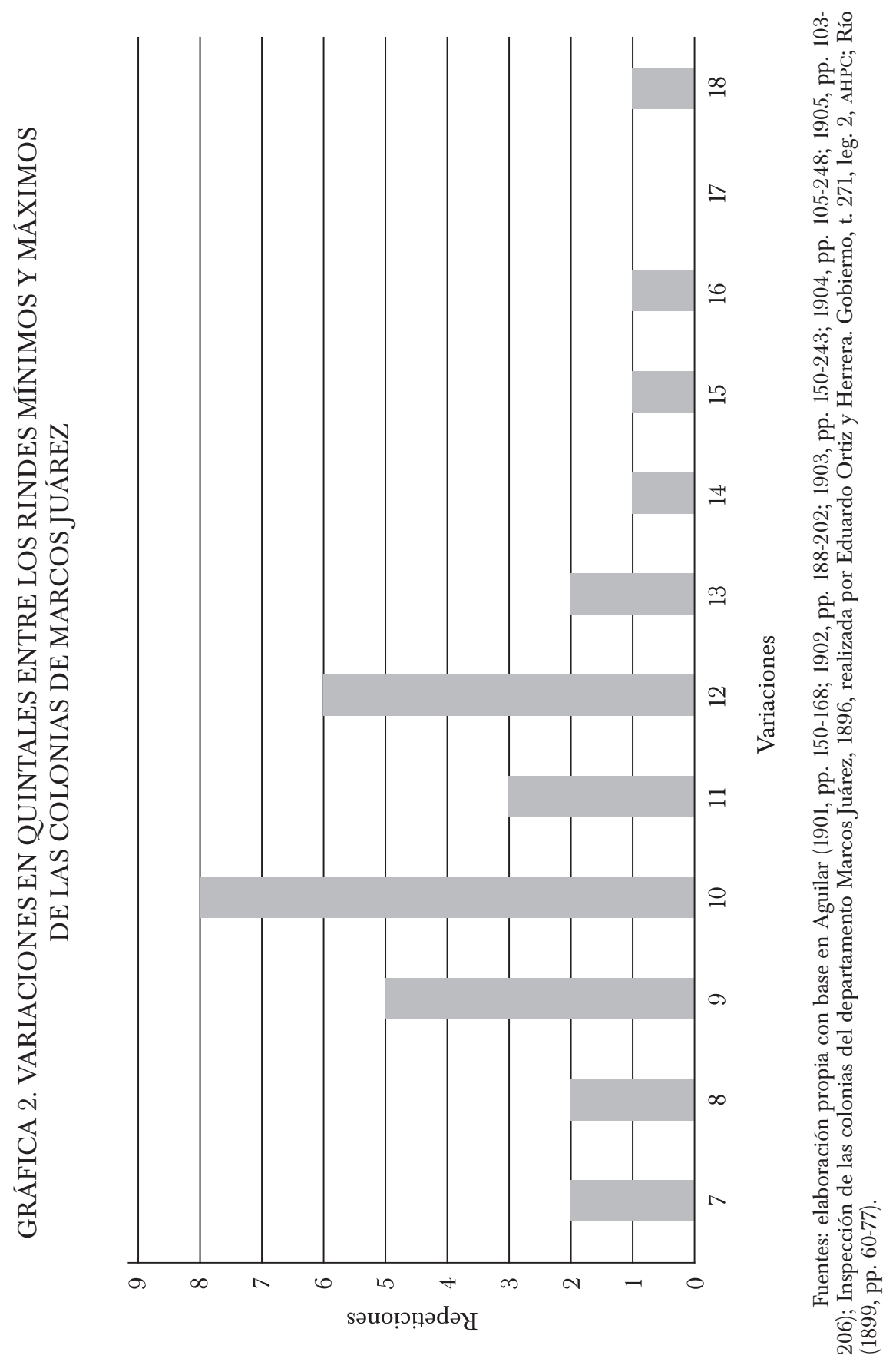




\section{CONCLUSIÓN}

En el desarrollo del artículo se ha puesto en un primer plano la problemática relacionada con transformar las tierras vírgenes en cultivables, tanto en lo referido a los trabajos necesarios para concretar este cambio, como en lo concerniente a las fluctuaciones que sufrieron las cosechas en el trascurso en el que se lo llevó a cabo.

Asimismo, se destacaron las restricciones que operaron para llevar adelante ese proceso. Por un lado se advirtieron las limitaciones que existieron para que innovaciones tecnológicas, como la tracción a vapor, redujeran los tiempos de esa operación. Por otro lado, se explicaron las razones por las cuales resultaba oneroso recurrir a la mano de obra asalariada para realizarlo.

En ese sentido, además de los argumentos sostenidos por la literatura sobre la conveniencia de las distintas modalidades de arriendo, al reducir los costos de vigilancia intrínsecos a la misma actividad agraria (Federico, 2006), se puso de manifiesto que la mayor variabilidad -que afectó a los rendimientos del trigo durante la transformación del suelo- imposibilitó el cálculo sobre los ingresos esperados frente a la inflexibilidad que imponían los salarios.

Los argumentos señalados se utilizaron para demostrar que el arriendo se ajustaba mejor a las restricciones edafológicas, a las presiones impuestas por la intensidad que adquirió la expansión de los cultivos y las fuertes oscilaciones que mostraron las cosechas de una a otra campaña. A su vez, y en relación con el contrato de renta fija, se evidenció que sus limitaciones no obedecieron tanto a las fluctuaciones en el valor del dinero local, como en general consideró la literatura (Arcondo, 1996; Gallo, 1983), pues tal como se constató el arriendo a porcentaje se difundió cuando aquellas cesaron.

En cambio, se situó la dificultad del contrato a renta fija en que sólo ofreció una solución parcial al dilema de expandir el proceso de transformación del suelo, demandado por los terratenientes, y preservar las ventajas de una explotación ampliada para los agricultores. Aquella forma contractual satisfacía, fundamentalmente, a los primeros.

Asimismo, y a diferencia de lo sostenido por una parte de la literatura que consideró la conveniencia del contrato a porcentaje en cuanto permitió a los arrendatarios destinar su ingreso al capital de trabajo (Sábato, 1988), se situó su ventaja en que brindó a los agricultores la posibilidad de permanecer sobre las parcelas y aprovechar las transformaciones incrementales efectuadas en el suelo. Su conveniencia se hizo más patente durante el periodo en el cual la proporción de las tierras vírgenes superaba a las cultivables, pues como lo sugiere la evidencia reunida las oscilacio- 
nes en las cosechas fueron mayores. Las cifras de los rendimientos así lo indican. En más de una ocasión el trabajo invertido en la roturación fue el único resultado concreto del esfuerzo realizado por quienes se abocaron a la actividad agrícola.

Pero la difusión de la aparcería se produjo cuando el ciclo climático expuso en toda su magnitud el problema para ambas partes y, fundamentalmente, para los terratenientes. Para continuar con el proceso de roturación de la tierra aún virgen y para que no se perdieran las mejoras ya realizadas, necesitaron de un contrato cuyo costo, por el uso del suelo, se expresara en una proporción del resultado. De este modo, evitaron que las deudas generadas por los fracasos, tan omnipresentes en la producción triguera, constituyeran un estímulo para el abandono de la parcela y para que la transformación antes señalada no quedara incompleta.

\section{LISTA DE REFERENCIAS}

Aguilar, E. (1901). Anuario de la Dirección General de Estadística de la Provincia de Córdoba correspondiente al año 1900. Córdoba: Domenici.

Aguilar, E. (1902). Anuario de la Dirección General de Estadística de la Provincia de Córdoba correspondiente al año 1901. Córdoba: Domenici.

Aguilar, E. (1903). Anuario de la Dirección General de Estadística de la Provincia de Córdoba correspondiente al año 1902. Córdoba: Domenici.

Aguilar, E. (1904). Anuario de la Dirección General de Estadística de la Provincia de Córdoba correspondiente al año 1903. Córdoba: Domenici.

Aguilar, E. (1905). Anuario de la Dirección General de Estadística de la Provincia de Córdoba correspondiente al año 1904. Córdoba: Domenici.

Aguilar, E. (1907). Campaña agrícola 1906-1907. Dirección General de Estadística y Agricultura. Córdoba: La Italiana.

Albarracín, S. (1889). Bosquejo histórico, político y económico de la provincia de Córdoba. Buenos Aires: Coni.

Arcondo, A. (1996). En el reino de Ceres. La expansión agraria en Córdoba 1870-1914. Córdoba: Universidad Nacional de Córdoba.

Carreras-Marín, A. y RAYes, A. (2015). La fiabilidad en la distribución geográfica de las exportaciones argentinas, 1875-1913. América Latina en la Historia Económica, 22(3), 177-212. DOI: 10.18232/alhe.v22i3.654

CORTÉs, R. (1997). La economía argentina en el largo plazo (siglos XIX y XX). Buenos Aires: Sudamericana/Universidad de San Andrés.

DíAZ-Alejandro, C. F. (1983). Ensayos sobre la historia económica argentina. Buenos Aires: Amorrortu.

Djenderedjian, J. (2008). La colonización agrícola en Argentina, 1850-1900. Problemas y desafíos de un complejo proceso de cambio productivo en Santa Fe y Entre 
Ríos, América Latina en la Historia Económica, 15(2), 129-157. DOI: 10.18232/alhe. v15i2.396

Djenderedjian, J., Bearzotti, S. y Martirén, J. L. (2010). Historia del capitalismo agrario pampeano. Expansión agrícola y colonización en la segunda mitad del siglo XIX (vols. 1-2). Buenos Aires: Teseo.

FEDERICO, G. (2006). The "real" puzzle of sharecropping: why is it disappearing? Continuity and Change, 27(2), 261-285. DOI: 10.1017/S0268416006005947

Ford, A. (1975). La Argentina y la crisis de la Baring de 1890. En M. Giménez (ed.), El régimen oligárquico. Materiales para el estudio de la realidad argentina (hasta 1930) (pp. 116-141). Buenos Aires: Amorrortu.

GALlO, E. (1983). La pampa gringa. Buenos Aires: Sudamericana.

García-Delgado, J. (1898). Memoria de las colonias. Año agrícola 1897-1898. En CóRdoba, Compilación de leyes, decretos y demás disposiciones de carácter público dictadas por el Departamento de Hacienda de la provincia de Córdoba en el año de 1898 (pp. 73183). Córdoba: La Italiana.

Gerchunoff, P., Rocchi, F. y Rossi, G. (2008). Desorden y progreso. Las crisis económicas argentinas 1870-1905. Buenos Aires: Edhasa.

KAERGER, K. [1901] (2004). La agricultura y la colonización en Hispanoamérica. Los Estados del Plata. Buenos Aires: Academia Nacional de la Historia.

Martínez, A., Latzina, F., León-Suárez, J. y Lahite, E. (1909). Censo Agropecuario Nacional. La ganadería y la agricultura en 1908 (vols. 1-3). Buenos Aires: Talleres de Publicaciones de la Oficina Meteorológica Argentina.

Martirén, J. L. (2013). La mies madura. Colonización agrícola y crecimiento económico en Santa Fe durante la segunda mitad del siglo XIX (Tesis de doctorado). Universidad Nacional del Centro de la Provincia de Buenos Aires, Argentina.

MARTiRÉn, J. L. (2014). Una mirada a los factores. La productividad del cultivo del trigo en la provincia de Santa Fe durante la gran expansión. Inédito. XXIV Jornadas de Historia Económica. Rosario.

MARTiRÉn, J. L. (2015). El fin del yermo. La emergencia de un nuevo mercado inmobiliario rural y los precios de la tierra en la provincia de Santa Fe, Argentina (18601895). Mundo Agrario, 16(32). Recuperado de http://www.mundoagrario.unlp.edu. ar/article/view/MAv16n32a01

Miatello, H. (1904). Investigación agrícola de la provincia de Santa Fe. Buenos Aires: Compañía Sudamericana de Billetes de Banco.

Moreyra, B. I. (1992). La producción agropecuaria cordobesa, 1880-1930 (Cambios, transformaciones y permanencias). Córdoba: Centro de Estudios Históricos.

Palacio, J. M. (1992). Arrendatarios agrícolas en una empresa ganadera. El caso de “Cruz de Guerra”, 1927-1938. Desarrollo Económico, 127(32), 381-409.

Palacio, J. M. (2004). La paz del trigo. Cultura legal y sociedad local en el desarrollo agropecuario pampeano, 1890-1945. Buenos Aires: Edhasa.

Reguera, A. (1993). Arrendamiento y formas de acceso a la producción en el sur bonaerense: el caso de una estancia del partido de Necochea, primera mitad del 
siglo Xx. En R. MANDrini y A. Reguera, Huellas en la tierra. Indios, agricultores y hacendados en la pampa bonaerense (pp. 241-274). Tandil: Instituto de Estudios Histórico Sociales.

Río, M. E. (1899). Inspección del señor Eduardo Ortiz y Herrera correspondiente a la campaña agrícola 1898-99. En La colonización en Córdoba en 1898-99 (pp. 60-77). Buenos Aires: Coni.

Río, M. E. y Achaval, L. (1905). Geografía de la provincia de Córdoba (vols. 1-2). Buenos Aires: Compañía Sudamericana de Billetes.

SÁbato, J. (1988). La clase dominante en la Argentina moderna, formación y características. Buenos Aires: Grupo Editor Latinoamericano.

Scobie, J. R. (1982). Revolución en las pampas. Historia social del trigo argentina, 1860-1910. Buenos Aires: Solar.

Tognetti, L. A. (2014). Arriendo y aparcería en el sureste cordobés a fines del siglo XIX. Actas de las XXIV Jornadas de Historia Económica. Argentina. Recuperado de http://www.aahe.fahce.unlp.edu.ar/jornadas-de-historia-economica/ xxiv-jornadas-de-historia-economica

ZEBERIO, B. (1993). La situación de los chacareros arrendatarios en la pampa húmeda. Una discusión inacabada. En R. MANDrini y A. Reguera, Huellas en la tierra. Indios, agricultores y hacendados en la pampa bonaerense (pp. 209-239). Tandil: Instituto de Estudios Histórico Sociales.

\section{Archivos}

AGN Archivo General de la Nación, Buenos Aires, Argentina.

AHPC Archivo Histórico Provincial de Córdoba, Córdoba, Argentina. 